\title{
Credibility Beliefs towards Nicotine Replacement Therapy and Exercise as Smoking Cessation Aids
}

\author{
Amelia Tritter ${ }^{1}$, Lyndsay Fitzgeorge ${ }^{1}$, Stefanie De Jesus ${ }^{1}$, Therese Harper ${ }^{1} \&$ Harry Prapavessis ${ }^{1}$ \\ ${ }^{1}$ School of Kinesiology, Western University, London, Canada \\ Correspondence: Amelia Tritter, School of Kinesiology, Western University, London, ON., N6A 3K7, Canada. \\ Tel: 1-519-661-2111 ext.81189. E-mail: atritter@uwo.ca
}

Received: March 18, 2014

doi:10.5539/ijps.v6n2p11
Accepted: March 28, $2014 \quad$ Online Published: May 20, 2014

URL: http://dx.doi.org/10.5539/ijps.v6n2p11

\begin{abstract}
Objective: The aim of the current study was to examine smokers' beliefs towards the credibility of exercise and Nicotine Replacement Therapy (NRT) as cessation aids while partaking in a quit-smoking program. Method: A subsample $(n=149)$ of female smokers underwent a 14-week cessation program involving exercise and NRT. Credibility beliefs were collected at baseline (before quitting), week 5 (one week after quitting), and week 14 (end of program). Smoking status was assessed at week 14 by breath expired into a carbon monoxide (CO) reader. Participants who demonstrated a $\mathrm{CO}$ score of $<6 \mathrm{ppm}$ were considered "quitters" and those who had levels of $\geq 6$ ppm or failed to attend the assessment were considered "smokers". Results: Quitters' exercise and NRT credibility beliefs significantly increased over time; however, no treatment by time interaction effect was found. No significant differences were found between smokers' and quitters' exercise and NRT credibility beliefs assessed at baseline. A significant difference was found between smokers' and quitters' week 5 exercise credibility scores, but not for week 5 NRT. Conclusions: For clinicians prescribing exercise as a smoking cessation aid, it is recommended that their patients' treatment credibility beliefs be assessed and reinforced, particularly during their first week of quitting.
\end{abstract}

Keywords: credibility, acute exercise, nicotine replacement therapy, smoking cessation, clinical recommendation

\section{Introduction}

An array of psychotherapy research has revealed that patients' initial beliefs towards the efficacy of a treatment are a strong predictor of treatment success (e.g., Friedman, 1963; Goldstein, 1960; Kirsch, 1999; Nau, Caputo, \& Borkovec, 1974). These cognitions can be classified as two distinct variables: expectancy and credibility (Borkovec \& Nau, 1972; Devilly \& Borkovec, 2000). Treatment expectancy refers to improvements the patient believes will be achieved personally, whereas treatment credibility refers to how believable, convincing, and logical the treatment seems (Devilly \& Borkovec, 2000). Patients' beliefs regarding the credibility of psychotherapies have shown to influence treatment effectiveness for various health concerns, including depression (Addis \& Jacobson, 2000), general anxiety disorder (Borkovec, Newman, Pincus, \& Lytle, 2002), and posttraumatic stress disorder (Taylor, 2003). Given the positive impact credibility has shown to have on treatment outcome, attempting to strengthen this cognition provides a potential avenue for improving treatment effectiveness.

Substantial research has supported the efficacy of both non-pharmacological and pharmacological smoking cessation aids; however, six-month cessation rates for even the most effective treatment modalities remain low at less than 30\% (Fiore, Jaén, \& Baker, 2008). Given the positive effect that treatment credibility has elicited in psychotherapies, it represents a prospective variable worth examining in the realm of smoking cessation. To date, no research has been dedicated to examining smokers' beliefs towards the credibility of cessation aids.

To better understand credibility beliefs, it is important to examine how they unfold naturally over time. Credibility is a perception that emerges from one's knowledge gained through direct experience or observation of a treatment (Schulte, 2008; Tinsley, Bowman, \& Ray, 1988); hence credibility beliefs are bound to fluctuate over the course of treatment. Distinguishing between patients' initial credibility beliefs and those that emerge with personal experience is important because initial beliefs are thought to influence clients' decisions to enter 
therapy and remain in therapy (Parham \& Tinsley, 1980), whereas emergent beliefs are thought to moderate treatment outcome (Perotti \& Hopewell, 1980). Unfortunately, credibility beliefs have typically been measured on one occasion, at baseline (Constantino, Glass, Arnkoff, Ametrano, \& Smith, 2011; Dozois \& Westra, 2005; Schulte, 2008). Examining credibility beliefs dynamically will highlight when credibility beliefs are strongest and potentially provide insight into what point of treatment is optimal to intervene and attempt to strengthen these beliefs in order to improve cessation rates.

The variability of credibility beliefs between different treatment modalities also warrants examination. Front line pharmacotherapies, such as Nicotine Replacement Therapy (NRT), have been scientifically proven and publicly recognized as valid quit smoking aids for years (Stead et al., 2012) and therefore would be expected to be highly credible. Conversely, alternative cessation strategies, such as exercise, which has shown to yield craving (Roberts, Maddison, Simpson, Bullen, \& Prapavessis, 2012) and to a lesser extent, cessation (Marcus et al., 1999) benefits would likely be less accepted by the general public and medical community as an effective quit strategy. Identifying whether or not exercise is perceived to be a credible smoking cessation aid compared to NRT will provide insight as to what aid should be advocated for when aiming to bolster treatment credibility beliefs. Prior to intervening and manipulating NRT and exercise credibility beliefs, it must also be determined whether these credibility beliefs are in fact predictors of treatment success and at what point these beliefs have the strongest influence.

With the above issues in mind, the purposes of the present study are to: 1) Examine successful quitters' exercise and NRT credibility beliefs over time; 2) Compare quitters' credibility beliefs between a well-established smoking cessation modality (i.e., NRT) against a lesser known one (i.e., exercise); and 3) Examine if smokers' beliefs regarding the credibility of NRT and exercise as quit-smoking aids predict their smoking status at the end of a 14-week cessation program.

\section{Methods}

\subsection{Participants}

A subsample of 149 females was derived from a smoking cessation clinical trial (NCT01305447), Getting Physical on Cigarettes (GPOC; Jung, Fitzgeorge, Prapavessis, Faulkner, \& Maddison, 2010). Participants were between 18 and 70 years of age, smoked greater than 10 cigarettes per day for at least the previous two years, and enrolled with hopes to quit smoking. Participants were required to provide written consent from a physician that approved the use of NRT and regular exercise and those with any contraindications were excluded. The host institution's Research Ethics Board (\#16306) granted ethical approval and written consent was obtained.

\subsection{Measures}

\subsubsection{Demographic Information and Smoking History}

Participant demographic information and smoking history can be found in Table 1.

Table 1. Demographic measures and smoking characteristics

\begin{tabular}{ll}
\hline Variable & $\mathrm{M}(\mathrm{SD}), \%$ \\
\hline Demographics: & \\
$\quad$ Age & $42.01(13.02)$ \\
Language spoken at home (\% English) & $96.8 \%$ \\
Yearly household income & \\
$\quad$ Below \$50,000 & $47.3 \%$ \\
$\quad$ Between \$50,000 and \$75,000 & $17.2 \%$ \\
$\quad$ Above \$75,000 & $35.5 \%$ \\
Number of children & $2.06(1.98)$ \\
Employed (\%) & $73.6 \%$ \\
Student (\%) & $12.1 \%$ \\
Unemployed (\%) & $14.3 \%$ \\
\hline
\end{tabular}




\begin{tabular}{ll} 
Smoking behaviour: & \\
Number of cigarettes per day & $16.55(6.29)$ \\
Number of years smoking & $18.48(12.74)$ \\
Fagerström test of nicotine dependence & $5.20(1.97)$ \\
Percentage of family and friends that smoke & \\
$\quad$ Between 0 and $10 \%$ & $34.4 \%$ \\
Between 10 and $20 \%$ & $16.7 \%$ \\
Above $20 \%$ & $51.1 \%$ \\
Number of previous quit attempts & $4.56(4.23)$ \\
\hline
\end{tabular}

\subsubsection{Smoking Status}

Smoking status was assessed at baseline (i.e., before quitting) and post-intervention at week 14 (i.e., after quitting) by breath expired into a carbon monoxide (CO) reader (Micro Smokerlyzer, Bedfont Scientific). Participants who provided a CO reading of less than six ppm were considered "quitters", whereas those who had levels equal to or greater than six ppm were considered "smokers". Participants who failed to attend the week-14 assessment were considered smokers.

\subsubsection{Treatment Credibility}

The treatment credibility/expectancy questionnaire (CEQ; Devilly \& Borkovec, 2000) was adapted for use in the current study, consisting of seven items: three related to expectancy, three related to credibility, and one which asked how important quitting smoking was to the individual (question 5). With the exception of question 5, participants provided two responses for each item to assess beliefs towards both treatment modalities (i.e., exercise and NRT). Responses were rated on a 9-point scale ranging from one (not at all) to nine (extremely). In line with the purpose of the study, the two credibility items that assessed beliefs towards quitting smoking behaviour (i.e., how logical do the quit smoking aids offered to you seem? how confident would you be in recommending these treatments to a friend who wants to quit smoking?) were included. The credibility item specific to craving and withdrawal symptoms (i.e., how successfully do you think these treatments will manage your craving and withdrawal symptoms?) was excluded because it lacked congruency with the quitting behaviour (i.e., smoking status) being assessed. A credibility score was calculated for each treatment modality by averaging the responses of the two items. The CEQ was administered at baseline, week 5, and week 14 to examine change over time. The CEQ participant data pertaining to expectancy were examined in Harper and colleagues' publication (Harper, Fitzgeorge, Tritter, \& Prapavessis, 2012); these data were excluded from the present research. The CEQ has shown good test-retest reliability (Devilly \& Borkovec, 2000) and the two credibility items pertaining to cessation demonstrated high internal consistency $(\alpha>.70)$ for NRT and exercise at all time points.

\subsection{Procedure}

Participants engaged in a 14-week exercise program at the Exercise and Health Psychology Laboratory (www.ehpl.uwo.ca) at Western University. The aerobic exercise program consisted of three sessions per week for the first eight weeks, two sessions per week for the next three weeks, and one session per week for the last three weeks. The exercise sessions ranged from 20-30 minutes and progressively increased to an intensity of $>$ $70 \%$ of participants' heart-rate reserve. On the fourth week of the exercise program, participants initiated their quit attempt and commenced a 10 -week step down NRT transdermal patch program (six weeks-21 mg; two weeks-14 mg; two weeks—-7 mg).

Participants' smoking status was determined at week 14, following completion of both the exercise and NRT programs. The questionnaire pertaining to participants' perceived treatment credibility beliefs was completed at baseline (before starting the exercise program), week 5 of regular exercise (one week after quitting smoking and starting the $21 \mathrm{mg}$ patch) and week 14 (end of the exercise and NRT programs).

\subsection{Statistical Analyses}

A factorial (NRT vs. exercise) repeated measures (baseline, week 5, week 14) ANOVA was used to examine change in quitters' treatment credibility scores over time as well as a treatment by time interaction effect. 
Separate ANOVAs, with an applied Bonferroni adjustment, were conducted to determine if exercise and NRT credibility beliefs, assessed at baseline and week 5, predicted smoking status at the end of the 14-week program.

\section{Results}

\subsection{Changes in Quitters' Credibility Beliefs}

Among those who successfully quit smoking at week 14 and completed the CEQ at the three time points $(n=$ 51 ), exercise and NRT credibility beliefs significantly increased over time, $F(2,99)=16.14, p<.001, \eta_{\rho}^{2}=.25$. However, no treatment by time interaction effect was found, $F(2,99)=1.05, p=.354, \eta_{\rho}^{2}=.02$. Credibility scores can be found in Table 2 .

Table 2. Changes in quitters' credibility beliefs

\begin{tabular}{llllll}
\hline & & \multicolumn{2}{c}{ Exercise Credibility } & \multicolumn{2}{c}{ NRT Credibility } \\
\cline { 3 - 6 } Assessment & $n$ & $M$ & $S D$ & $M$ & $S D$ \\
\hline Baseline & 51 & 7.51 & 1.28 & 7.28 & 1.45 \\
Week 5 & 51 & 8.28 & 1.06 & 7.90 & 1.48 \\
Week 14 & 51 & 8.31 & 1.02 & 8.28 & .96 \\
\hline
\end{tabular}

\subsection{Baseline Credibility Beliefs and Week 14 Smoking Status}

Three of the 149 participants were excluded from the analysis because they failed to complete the CEQ at baseline, two of which were classified as smokers at week 14 and one of which was classified as a quitter at week 14. Baseline credibility scores can be found in Table 3. No significant difference was found between smokers' $(n=84)$ and quitters' $(n=62)$ in baseline exercise, $F(1,144)=2.77, p=.098, \eta^{2}=.019$ or NRT, $F(1,144)=2.77, p=.098, \eta^{2}=.019$, credibility beliefs.

Table 3. Baseline credibility beliefs and smoking status

\begin{tabular}{lllllll}
\hline & \multicolumn{3}{c}{ Exercise Credibility } & \multicolumn{4}{c}{ NRT Credibility } \\
\cline { 2 - 7 } Week 14 Smoking Status & $n$ & $M$ & $S D$ & $n$ & $M$ & $S D$ \\
\hline Quitters & 62 & 7.56 & 1.35 & 62 & 7.31 & 1.45 \\
Smokers & 84 & 7.14 & 1.58 & 84 & 6.86 & 1.77 \\
\hline
\end{tabular}

\subsection{Week 5 Credibility Beliefs and Week 14 Smoking Status}

Of the 149 participants, 40 failed to complete the CEQ at week 5, 28 of which were classified as smokers at week 14 and 12 of which were classified as quitters at week 14 . Week 5 credibility scores can be found in Table 4. A significant difference was found between smokers' $(n=52)$ and quitters' $(n=57)$ week 5 exercise credibility scores, $F(1,107)=8.20, p=.005, \eta^{2}=.071$. However, no significant difference in week 5 NRT credibility scores, $F(1,107)=2.32, p=.131, \eta^{2}=.021$ was found between smoking status groups. 
Table 4 . Week 5 credibility beliefs and smoking status

\begin{tabular}{lllllll}
\hline & \multicolumn{3}{c}{ Exercise Credibility } & \multicolumn{4}{c}{ NRT Credibility } \\
\cline { 2 - 7 } Week 14 Smoking Status & $n$ & $M$ & $S D$ & $n$ & $M$ & $S D$ \\
\hline Quitters & 57 & 8.32 & 1.04 & 57 & 7.98 & 1.43 \\
Smokers & 52 & 7.61 & 1.53 & 52 & 7.49 & 1.93 \\
\hline
\end{tabular}

\section{Discussion}

Our study provides novel and important information on patients' credibility beliefs towards smoking cessation strategies (i.e., exercise and NRT patch) in terms of changes over time, a comparison between the two modalities, and how credibility beliefs before and during treatment influence post-treatment smoking cessation success.

Participants who successfully quit smoking (by week 14) demonstrated an increase in credibility scores for exercise and NRT cessation aids from baseline (pre-quit) to post-treatment (week 14). This increase is consistent with the work of Newman and Fisher (2010) who found that patients with general anxiety disorder receiving cognitive and behavioural therapy perceived the treatments to be more credible over time. Based on psychological theories, it is reasonable to assume that credibility beliefs will be influenced throughout the course of treatment as participants engage in the treatment modalities. For one, self-efficacy to complete the exercise regime and adhere to the NRT protocol is likely to increase with previous successful performance (Bandura, 1977). In addition, cognitive dissonance theory predicts that after individuals invest in a form of treatment they will positively align their beliefs in the techniques to match their investment in order to justify their efforts (Festinger, 1957).

Credibility beliefs for the cessation aids increased at a similar rate (i.e., no difference between treatments over time). This can be interpreted as quitters perceiving exercise to be just as credible as NRT and retrospectively attributing their success to both treatment modalities equally. By demonstrating that the public's perception of a novel treatment aid (i.e., exercise) is comparable to that of a traditional well-established pharmaceutical product (i.e., NRT) holds promise for the acceptance and increase use of alternative cessation aids.

In regards to credibility beliefs impacting smoking cessation success, emergent exercise credibility (exercise credibility assessed at week 5-one week post-quit) was the only variable that predicted quit-smoking success at the end of the 14-week program. In other words, those with higher credibility scores towards exercise assessed one week post-quit were more likely to be smoke-free at the end of the program. This credibility effect supports previous studies where beliefs regarding the credibility of psychotherapies have shown to influence treatment effectiveness for various health concerns (e.g., Addis \& Jacobson, 2000; Borkovec et al., 2002; Taylor, 2003).

Our data suggests that credibility may be a mechanism by which exercise influences its effect on quit success; however, this effect was not found with NRT. We can only speculate as to the reason for this difference. The nature of the treatments used may differ in terms of their influence by a psychological construct, such as credibility beliefs. Nicotine Replacement Therapy is a pharmacotherapy that may influence smokers trying to quit exclusively in a physiological manner, whereas exercise may elicit its effect through both physiological and psychological pathways. Therefore, it is plausible that the latter treatment may be more easily influenced by psychological factors.

To better understand the relationship between smoking cessation treatments and credibility beliefs, the mechanisms through which credibility operates must be examined. Turning to the expectancy literature may serve as a valid starting point for investigating such mechanisms as it has been researched more exhaustively than credibility. In a sample of anxious patients undergoing cognitive-behavioural therapy, Westra and colleagues (2007) found that higher expectations were related to greater homework compliance and subsequently to decreased anxiety. In addition, therapeutic alliance - the collaborative relationship between patient and therapist in the common fight to overcome the patient's suffering and self-destructive behaviour (Bordin, 1979) - has been found to moderate the expectancy-treatment outcome link in depressed patients receiving psychotherapy and pharmacotherapy (e.g., Meyer et al., 2002). Given these findings, future work should investigate whether smokers' compliance to an exercise regime and/or their relationship with an exercise leader explains how credibility exerts its effect. 
It is worth noting that the credibility effect observed might be a conservative estimate. For one, there were more smokers who didn't provide week 5 data than quitters. In addition, the credibility scores of this voluntary sample were of a narrow range and high on the continuum. Therefore, this effect may be stronger if evaluated in the general smoking population who had not participated in a research study and been educated on the cessation aids.

One approach that holds promise to improving smoking cessation rates is through the involvement of clinicians. In countries with accessible primary health care, clinicians have frequent contact with patients and opportunity to intervene. Furthermore, clinicians are expected to enquire about patients' smoking status and are viewed as a credible source in regards to advising about smoking cessation (Russell, Wilson, Taylor, \& Baker, 1979). The association found in the present study between treatment credibility and quit success highlights the importance of clinicians assessing and fostering smokers' perceptions of the credibility of exercise when prescribing this cessation aid. Credibility beliefs can be evaluated informally through patient-clinician dialogue and as well through formal measurement (e.g., CEQ; Devilly \& Borkovec, 2000). In line with the results of the present study, it is imperative that clinicians not only aim to bolster credibility beliefs when exercise regimes are prescribed but also while participants are undergoing the quit attempt.

Clinicians may strengthen smokers' credibility beliefs by providing them with a therapeutic rationale prior to treatment. This strategy would involve clinicians addressing unreasonable outcome expectations, preparing patients for what the treatment will be like (e.g., common symptoms), explaining the underlying mechanisms of the treatment, strengthening patients' confidence that treatment will be beneficial, and ensuring that their goals are aligned with the patients' (Newman \& Fisher, 2010). Previous studies demonstrate that expectancy and credibility can be influenced significantly by delivering an initial therapeutic rationale. For example, Hardy and colleagues (1995) discovered an empirical change in credibility beliefs of depressed clients after the delivery of an initial cognitive behaviour therapy rationale. As highlighted in the present study, clinicians should aim to bolster patients' credibility beliefs that emerge over time. Therefore, any information conveyed to smokers' prior to quitting that substantiates exercise as a cessation aid should be reiterated during the critical treatment period as well.

The patterns of results with respect to credibility over time and credibility-outcome relations reinforce the importance of maintaining the conceptual distinction between initial and emergent credibility. Furthermore, the difference between the predictive power of credibility beliefs for NRT and exercise highlights the importance of distinguishing between treatment modalities. Identifying the critical time period (i.e., one week post-quit) and the treatment modality that has the most influence on quit success (i.e., exercise) unveils information that has the potential to improve cessation rates. Thus, for clinicians prescribing exercise as a smoking cessation aid, it is recommended that their patients' treatment credibility beliefs be assessed and reinforced, particularly during their first week of quitting.

\section{Acknowledgments}

This research was supported by the Canadian Cancer Society Research Institute (P.I. Dr. Harry Prapavessis; Grant \# 019876).

\section{References}

Addis, M. E., \& Jacobson, N. S. (2000). A closer look at the treatment rationale and homework compliance in cognitive-behavioral therapy for depression. Cognitive Therapy and Research, 24(3), 313-326. http://dx.doi.org/10.1023/A:1005563304265

Bandura, A. (1977). Self-efficacy: Toward a unifying theory of behavioral change. Psychological Review, 84(2), 191-215. http://dx.doi.org/10.1037/0033-295X.84.2.191

Bordin, E. S. (1979). The generalizability of the psychoanalytic concept of the working alliance. Psychotherapy: Theory, Research \& Practice, 16(3), 252-260. http://dx.doi.org/10.1037/h0085885

Borkovec, T. D., \& Nau, S. D. (1972). Credibility of analogue therapy rationales. Journal of Behavior Therapy and Experimental Psychiatry, 3(4), 257-260. http://dx.doi.org/10.1016/0005-7916(72)90045-6

Borkovec, T. D., Newman, M. G., Pincus, A. L., \& Lytle, R. (2002). A component analysis of cognitive-behavioral therapy for generalized anxiety disorder and the role of interpersonal problems. Journal of Consulting and Clinical Psychology, 70(2), 288-298. http://dx.doi.org/10.1037/0022-006X.70.2.288

Constantino, M. J., Glass, C. R., Arnkoff, D. B., Ametrano, R. M., \& Smith, J. Z. (2011). Expectations. In J. C. Norcross (Ed.), Psychotherapy relationships that work: Therapist contributions and responsiveness to 
patients (2nd ed., pp. 354-376). New York: Oxford University Press.

Devilly, G. J., \& Borkovec, T. D. (2000). Psychometric properties of the credibility/expectancy questionnaire. Journal of Behavior Therapy and Experimental Psychiatry, 31(2), 73-86. http://dx.doi.org/10.1016/S0005-7916(00)00012-4

Dozois, D. J. A., \& Westra, H. A. (2005). Development of the anxiety change expectancy scale (ACES) and validation in college, community, and clinical samples. Behaviour Research and Therapy, 43, 1655-1672. http://dx.doi.org/10.1016/j.brat.2004.12.001

Festinger, L. (1957). A theory of cognitive dissonance. Stanford, CA: Stanford University Press.

Fiore, M. C., Jaén, C. R., \& Baker, T. B. (2008). Treating tobacco use and dependence: 2008 update: Clinical practice guideline. Rockville, MD: U.S. Department of Health and Human Services: Public Health Services.

Friedman, H. J. (1963). Patient-expectancy and symptom reduction. Archives of General Psychiatry, 8(1), 61-67. http://dx.doi.org/10.1001/archpsyc.1963.01720070063007

Goldstein, A. P. (1960). Patient's expectancies and non-specific therapy as a basis for (UN) spontaneous remission. Journal of Clinical Psychology, 16(4), 399-403. http://dx.doi.org/10.1002/1097-4679(196010)16:4<399::

Hardy, G. E., Barkham, M., Shapiro, D. A., Reynolds, S., Rees, A., \& Stiles, W. B. (1995). Credibility and outcome of cognitive - behavioural and psychodynamic - interpersonal psychotherapy. British Journal of Clinical Psychology, 34(4), 555-569. http://dx.doi.org/10.1111/j.2044-8260.1995.tb01489.x

Harper, T., Fitzgeorge, L., Tritter, A., \& Prapavessis, H. (2012). Acute exercise effects on craving and withdrawal symptoms among women attempting to quit smoking using nicotine replacement therapy. Journal of Smoking Cessation, 7, 72-79. http://dx.doi.org/10.1017/jsc.2012.15

Jung, M. E., Fitzgeorge, L., Prapavessis, H., Faulkner, G., \& Maddison, R. (2010). The Getting Physical on Cigarettes trial: Rationale and methods. Mental Health and Physical Activity, 3(1), 35-44. http://dx.doi.org/10.1016/j.mhpa.2010.02.002

Kirsch, I. E. (1999). How expectancies shape experience. Washington, DC: American Psychological Association. http://dx.doi.org/10.1037/10332-000

Marcus, B. H., Albrecht, A. E., King, T. K., Parisi, A. F., Pinto, B. M., Roberts, M., ... Abrams, D. B. (1999). The efficacy of exercise as an aid for smoking cessation in women: A randomized controlled trial. Archives of Internal Medicine, 159(11), 1229-1234. http://dx.doi.org/10.1001/archinte.159.11.1229

Meyer, B., Pilkonis, P. A., Krupnick, J. L., Egan, M. K., Simmens, S. J., \& Sotsky, S. M. (2002). Treatment expectancies, patient alliance and outcome: Further analyses from the National Institute of Mental Health Treatment of Depression Collaborative Research Program. Journal of Consulting and Clinical Psychology, 70(4), 1051-1055. http://dx.doi.org/10.1037/0022-006X.70.4.1051

Nau, S. D., Caputo, J. A., \& Borkovec, T. D. (1974). The relationship between credibility of therapy and simulated therapeutic effects. Journal of Behavior Therapy and Experimental Psychiatry, 5(2), 129-133. http://dx.doi.org/10.1016/0005-7916(74)90098-6.

Newman, M. G., \& Fisher, A. J. (2010). Expectancy/credibility change as a mediator of cognitive behavioral therapy for generalized anxiety disorder: Mechanism of action or proxy for symptom change? International Journal of Cognitive Therapy, 3, 245-261. http://dx.doi.org/10.1521/ijct.2010.3.3.245

Parham, W. D., \& Tinsley, H. E. (1980). What are friends for? Students' expectations of the friendship encounter. Journal of Counseling Psychology, 27(5), 524-527. http://dx.doi.org/10.1037/0022-0167.27.5.524

Perotti, L. P., \& Hopewell, C. A. (1980). Expectancy effects in psychotherapy and systematic desensitization: A review. JSAS: Catalog of Selected Documents in Psychology, 10.

Roberts, V., Maddison, R., Simpson, C., Bullen, C., \& Prapavessis, H. (2012). The acute effects of exercise on cigarette cravings, withdrawal symptoms, affect, and smoking behaviour: Systematic review update and meta-analysis. Psychopharmacology, 222(1), 1-15. http://dx.doi.org/10.1007/s00213-012-2731-z

Russell, M. A. H., Wilson, C., Taylor, C., \& Baker, C. D. (1979). Effect of general practitioners' advice against smoking. British Medical Journal, 2(6184), 231-235. http://dx.doi.org/10.1136/bmj.2.6184.231

Schulte, D. (2008). Patients' outcome expectancies and their impression of suitability as predictors of treatment outcome. Psychotherapy Research, 18, 481-494. http://dx.doi.org/10.1080/10503300801932505 
Stead, L. F., Perera, R., Bullen, C., Mant, D., Hartmann-Boyce, J., Cahill, K., \& Lancaster, T. (2012). Nicotine replacement therapy for smoking cessation. Cochrane Database of Systematic Reviews, 11(11). http://dx.doi.org/10.1002/14651858.CD000146.pub4

Taylor, S. (2003). Outcome predictors for three PTSD treatments: Exposure therapy, EMDR, and relaxation training. Journal of Cognitive Psychotherapy: An International Quarterly, 17, 149-162. http://dx.doi.org/10.1891/jcop.17.2.149.57432

Tinsley, H. E. A., Bowman, S. L., \& Ray, S. B. (1988). Manipulation of expectancies about counseling and psychotherapy: Review and analysis of expectancy manipulation strategies and results. Journal of Counseling Psychology, 35, 99-108. http://dx.doi.org/10.1037/0022-0167.35.1.99

Westra, H. A., Dozois, D. J., \& Marcus, M. (2007). Expectancy, homework compliance, and initial change in cognitive-behavioral therapy for anxiety. Journal of Consulting and Clinical Psychology, 75(3), 363-373. http://dx.doi.org/10.1037/0022-006X.75.3.363

\section{Copyrights}

Copyright for this article is retained by the author(s), with first publication rights granted to the journal.

This is an open-access article distributed under the terms and conditions of the Creative Commons Attribution license (http://creativecommons.org/licenses/by/3.0/). 